\title{
SE ESTOU NO GOOGLE, LOGO EXISTO: TÉCNICAS DE ALAVANCAGEM E VISIBILIDADE DE UM PERIÓDICO CIENTÍFICO EM MOTORES DE BUSCA POR MEIO DE TÉCNICAS DE SEO
}

\author{
IF I'M ON GOOGLE, SO EXIST: LEVERAGE AND \\ VISIBILITY STRATEGIES OF A SCIENTIFIC JOURNAL IN \\ SEARCH ENGINES USING SEO TECHNIQUES
}

\author{
Barbara Coelho Nevesa \\ Ramon Davi Santanab \\ Dulcinéia Vieira de Assunção Gomesc \\ Makson de Jesus Reis ${ }^{d}$
}

\begin{abstract}
RESUMO
Introdução: O artigo aborda o marketing digital pelo viés das técnicas de Search Engine Optimization (SEO) aplicadas ao caso do Website da revista científica PontodeAcesso Objetivo: Analisa aspectos e medidas objetivas e técnicas de SEO on-site e on-page que promovam a alavancagem da visibilidade do site e dos seus conteúdos publicados entre os principais resultados de pesquisa dos grandes motores de busca como Google, Bing e Yahoo!. Metodologia: O método é descritivo, com abordagem qualitativa, e metodologia de estudo de case (Revista) em marketing, com o apoio de revisão de literatura e técnica de observação a parir da criação de personas. Resultados: o texto apresenta de forma descritiva e fundamentada as observações realizadas a partir da análise na perspectiva do SEO on-site e on-page. Conclusões: o Website da PontodeAcesso não faz uso de tais estratégias e técnicas, o que tem colaborado para uma potencial invisibilidade ou baixa recuperação da sua produção científica na Web em resultados de mecanismos de busca a nível global. E que o uso de tais ferramentas poderiam alavancar sua visibilidade na comunidade científica e potencializar o engajamento.
\end{abstract}

a Doutora em Educação pela Universidade Federal da Bahia (UFBA). Docente de Tecnologia da Informação do Instituto de Ciência da Informação da Universidade Federal da Bahia (UFBA).E-mail: babi.coelho7@gmail.com.

b MBA em Gestão Pública pelo Centro Universitário Leonardo Da Vinci (Uniasselvi) e Bacharel em Biblioteconomia e Documentação pela Universidade Federal da Bahia (UFBA). Bibliotecário-Documentalista da pela Universidade Federal da Bahia (UFBA). E-mail: ramondsa@ufba.br.

c Mestranda do Programa de Pós-Graduação em Ciência da Informação pela Universidade Federal da Bahia (PGGCI-UFBA).E-mail: ducenf789@gmail.com.

d Doutorando do Programa de Pós-Graduação em Ciência da Informação pela Universidade Federal da Bahia (PGGCI-UFBA). E-mail: maksonacademico2@gmail.com. 
Descritores: Ferramentas de busca na Web. Marketing na Internet. Recuperação da informação. Search Engine Optimization (SEO). Periódico científico.

\section{INTRODUÇÃO}

Em uma sociedade cada vez mais conectada, os conteúdos digitais disponíveis em sites, redes sociais e plataformas têm sido a tônica dos últimos anos no sentido de produção de informação. A tão discutida Era da Informação originada após o fim da Segunda Guerra já é um fenômeno que aos poucos tem tomado forma por meio de avanços que se traduzem em tecnologias vestíveis, conectividade ubíqua, performatividades algorítmicas e Inteligência Artificial (IA).

Nesse mundo hiperconectado, a informação tem se multiplicado cada vez mais em telas de alta performance gráfica e de diversos tamanhos, disponíveis em qualquer lugar, a qualquer hora, sem a necessidade de intermediários além da própria conexão à Internet. Um "Ok, Google" é o suficiente para, em questão de segundos, sem um clique sequer, encontrar 0 que se deseja com relevância peculiar: resultados que mais se aproximam do que você buscaria ao que você efetivamente esperava encontrar. É simplesmente seu histórico, suas interações em redes sociais, suas leituras passadas, seus acessos mais rotineiros e, de repente, a camiseta com estampa do Star Wars que você comprou em um e-commerce, passa a recomendar, agora, suas leituras e o que, depois, você provavelmente vai gostar. Trata-se da serendipidade, ou o efeito de se encontrar o que, necessariamente, não se buscava.

Graças aos milionários investimentos das empresas de tecnologia do Vale do Silício, os motores de busca estão a cada dia mais eficientes. A indexação da informação global armazenada na Web, realizada por grandes players como a Google, Yahoo! e Bing, tem se preocupado cada vez mais com a qualidade da recuperação da infinidade de informação disponível na World Wide Web (WWW). Com as melhorias atribuídas aos seus algoritmos de busca, os dados podem ser encontrados com mais atributos de relevância e pertinência, aspectos que não era possível há alguns anos. Resguardando situações que envolvam 
competências educacionais, infocomunicacionais e de exclusão digital, percebese que a conversa de que na Internet tem muito, mas ao mesmo tempo pouco do que se aproveitar está ficando a cada 'clique' mais obsoleta.

Nesta empreitada, o marketing digital ocupou seu espaço e se aliou aos motores de busca. Logo, é tempo de estudar com um site, dentre bilhões de outros, podem se destacar nas SERPs ${ }^{1}$ de resultados de motores buscas populares, trazendo visibilidade para seu título, marca e seus conteúdos. Nesse contexto, a relevância deste artigo, está na consideração que a Ciência da Informação pode compreender de algumas estratégias que envolvem a Otimização de Motores de Busca, ou Search Engine Optimization (SEO), principalmente no que tange aos periódicos científicos. É sabido que a falta de aplicação de um marketing direcionado a qualquer produto ou serviço dificulta de certa forma o acesso e o uso, já que as pessoas precisam saber da existência para ter interesse pelo consumo (ARAÚJO; FREIRE; CÔRTES, 2018).

Nesse contexto, a recuperação da informação (RI) ganha ainda maior destaque, sendo entre as áreas estudadas pela Ciência da Informação $(\mathrm{Cl})$, a que se preocupa em disponibilizar a informação para satisfação de uma necessidade do usuário (VIEIRA; PINHO, 2015).

$\mathrm{O}$ artigo tem como objetivo geral descrever a estratégia de alavancagem e visibilidade para um periódico eletrônico em motores de busca por meio de técnicas de SEO. Especificamente irá abordar o marketing digital e as práticas de mercado; Apresentar as principais características do SEO na WEB; Estudar o case do website do periódico PontodeAcesso, a partir das medidas de SEO on-site e on-page.

Trata-se de pesquisa de marketing digital com abordagem do tipo qualitativa que segundo Virgilito (2018), propiciam que o pesquisador possa entender melhor algum assunto sobre o qual não se tem ou se tem pouco conhecimento, ou ainda para explorar conceitos. Para tanto, o método mais adequado é o descritivo, a metodologia utilizada foi com base em estudo de

1 SERP é abreviatura de Search Engine Results Page. É a página de resultados de um buscador na Web. 
caso com apoio da revisão de literatura sobre o tema proposto e a técnica de observação.

\section{MARKETING DIGITAL E AS PRÁTICAS DE MERCADO}

O marketing tem grande importância nas práticas de mercado e sua evolução vem acontecendo constantemente e de forma a se adequar às novas demandas na área comercial. Segundo Terblanche (2005) e Frederico (2008), há indícios de que as práticas de marketing sobre produtos e serviços existem desde antes de 7.000 a.C. (escambo, mercantilismo, alistamento em exércitos).

O surgimento do marketing na sociedade está atrelado a uma série de mudanças ocorridas ao longo dos anos que levaram à evolução econômica e sociocultural vivenciada atualmente. De acordo com Kotler (1997 apud FREDERICO, 2008), a evolução do marketing é composta por cinco fases, sendo elas: orientação à produção, orientação ao produto, orientação a vendas, orientação ao mercado e orientação ao marketing societal.

A Era da Produção é um período ocorrido entre 1900 e 1930 como resultado da Revolução Industrial que proporcionou mudanças de toda natureza nas sociedades e efetivamente no mercado, permitindo a ampliação das formas de consumo e demanda em todos os setores. Esse acontecimento fez com que as demandas superassem as ofertas no mercado de um modo geral (COBRA et al, 1992 apud MORETTI; OLIVEIRA; SOUZA, 2018).

Nesse período, o mercado não tinha a preocupação em atender 0 consumidor em suas necessidades e, além disso, não existia o cuidado em oferecer opções de produtos e serviços. A prioridade era aumentar a produção para atender a grande demanda existente e, assim, distribuí-la para consumo de forma mais eficiente.

Em seguida, não bastava apenas produzir para atender a demanda, era necessário investimento na produção e, então, as empresas começaram gradativamente a incorporar diferenciais no produto como qualidade e design. Essa fase é chamada de orientação ao produto (FREDERICO, 2008).

Posteriormente à fase de produção, veio o período de vendas, entre 
1930 e 1950, ao final da Segunda Guerra Mundial, quando o mercado voltou seu foco para as estratégias de promoção e vendas. Diferentemente do período anterior, nessa etapa a oferta era superior à demanda. Além disso, o mercado produzia volumosamente, mas a procura estava em baixa e, segundo acreditavam os pesquisadores, os consumidores não comprariam os produtos se não existisse um esforço substancial em sua promoção (BARTELS et al, 1976 apud MORETTI; OLIVEIRA; SOUZA, 2018). Nessa perspectiva, as empresas começaram a adotar sofisticadas técnicas de vendas e investimento em propaganda para poder vender seus estoques.

O período que se segue coloca o consumidor no centro dos negócios. A chamada Era do Marketing, ocorrida a partir de 1950, demonstra a preocupação das empresas com a satisfação das necessidades e desejos dos consumidores, o que até hoje se mostra como algo imprescindível para a sustentabilidade das empresas no mercado cada vez mais competitivo (ARANTES et al, 1975 apud MORETTI; OLIVEIRA; SOUZA, 2018).

Para Frederico (2008), o período de orientação ao marketing societal veio acontecer na fase em que as empresas se comprometeram em determinar e satisfazer as necessidades, desejos e interesses do mercado-alvo de forma mais eficaz que os competidores, e ainda preservou ou melhorou o bem-estar da sociedade.

As fases evolutivas do marketing proporcionaram o seu estabelecimento conceitual. No final da década de 1940 e início da década de 1950, surge o conceito atual de marketing, em que os objetivos organizacionais seriam alcançados com a superioridade competitiva, tendo a coordenação e integração das atividades e processos de marketing por toda a organização, de forma a reconhecer e satisfazer as necessidades e desejos dos consumidores e clientes das empresas (ARANTES et al, 1975 apud MORETTI; OLIVEIRA; SOUZA, 2018).

Segundo a Associação Americana de Marketing (1935),

[...] marketing é o desempenho de atividades que direcionam o fluxo de bens e serviços dos produtores aos consumidores. Conforme essa definição, há uma maior preocupação voltada para a utilidade econômica do vendedor onde a atividade de negócios é exercida de forma a maximizar a eficiência da 
produção e distribuição de bens e serviços. É a atividade, o conjunto de conhecimentos e os processos de criar, comunicar, entregar e trocar ofertas que tenham valor para consumidores, clientes, parceiros e sociedade como um todo (FREDERICO, 2008, p. 1).

Concomitantemente, o marketing é de fundamental importância no cenário econômico e social (NEVES, 2018). Ele desafia constantemente o mercado no sentido de prosperar financeiramente e, em alguns momentos, até mesmo a sobreviver. Além disso, é relevante o seu papel no enfrentamento dos desafios mercadológicos, uma vez que finanças, operações, contabilidade e outras funções organizacionais não terão sentido se não houver uma demanda por bens e serviços que seja suficiente para que o mercado obtenha lucro.

A importância do marketing na sociedade é abrangente. $E$ isso se deve ao fato de que novos produtos foram introduzidos e apresentados ao mercado e aos consumidores graças a sua evolução. Não obstante, foi através dele que tais produtos conquistaram aceitação do mercado e têm promovido melhoria na vida das pessoas.

Um marketing de sucesso gera demanda por produtos o que, por sua vez, cria postos de trabalho e contribui com os resultados financeiros do mercado. Ainda nesse sentido, ele permite que as empresas se envolvam de forma mais sólida em atividades socialmente responsáveis. É por isso que, muitas vezes, observamos o sucesso financeiro de uma empresa dependendo das habilidades e do sucesso das ações do departamento de marketing.

$\mathrm{Na}$ Era da Informação, onde há necessidade e preocupação das instituições com a Internet e conectividade, possibilitando as mensagens trocadas em tempo real, é importante reagir com rapidez e firmeza. Nesse contexto, o marketing precisa se adaptar e atender às evoluções de um mercado cada vez mais digital. No mundo virtual, o marketing sobre bens, produtos e serviços tem ganhado espaço com o avanço da Internet. A facilidade de busca diminui a distância entre informações e clientes e influencia na determinação da concorrência, ao deixar, por exemplo, os consumidores mais bem informados sobre os produtos ou serviços oferecidos. Além disso, permite que as empresas analisem o comportamento dos seus consumidores, 
Se estou no Google, logo existo: técnicas de alavancagem e visibilidade de um periódico científico em motores de busca por meio de técnicas de SEO

dos concorrentes e do ambiente competitivo para traçar suas estratégias empresariais (KOTLER, 2012).

Para Neves (2018, tradução livre), a missão do marketing no mundo conectado é lidar com os clientes, seja qual for o canal ou contexto em que estejam. Ainda segundo o autor, o antigo marketing - baseado numa visão reducionista voltada para o produto e não para as necessidades do consumidor - não atende plenamente aos novos rumos baseados nos processos informacionais (KOTLER, 1997 apud NEVES, 2018). E mais,

[...] recai sobre as fórmulas utilizadas em marketing. "Receitas de bolo", como a análise SWOT e do mix de marketing, podem ser aplicadas de forma simplista e não atender à complexidade das demandas atuais. A falta de profundidade com que esses temas são analisados, não traz benefícios às organizações. Ainda, mascaram a realidade. As organizações são narcisistas e não reconhecem suas vulnerabilidades e superestimam suas competências. (FREDERICO, 2008, p. 6).

Nesse sentido, o marketing envolve a identificação e a satisfação das necessidades humanas e sociais. Ele tem a capacidade de transformar uma necessidade particular ou social em uma oportunidade lucrativa de negócios. Esse perfil é característico das pessoas que trabalham com o marketing, pois elas decidem quais recursos projetar em um produto, estipular preços, onde vender bens ou oferecer serviços e quanto gastar com propaganda, vendas, Internet e marketing digital.

Essas decisões atualmente são tomadas em um ambiente fomentado pela Internet, onde consumidores, concorrência, tecnologia e forças econômicas e informacionais mudam rapidamente, podendo trazer consequências instantâneas. Nesse sentido, o marketing digital resulta de um cuidadoso processo de planejamento e execução, que utiliza as mais avançadas ferramentas e técnicas disponíveis (KOTLER; KARTAJAYA; SETIAWAN, 2017).

As transformações no mundo atualmente movidas em tempos da informação digital, afeta diretamente os processos que envolvem o marketing. Portanto, para Neves (2018), ter um Website na rede mundial de computadores, na atualidade, não é mais um investimento de pouca prioridade. Isto é, no contexto contemporâneo, trata-se de uma necessidade, 
visando a garantir a sobrevivência da instituição.

O marketing digital é extremamente favorecido com o avanço da Internet. No Brasil, por exemplo, os consumidores de classes mais populares já estão se habituando a utilizar e comprar por meio de lojas virtuais. Nisto, de acordo com Frederico (2008), a facilidade de busca proporcionada pelo marketing digital diminui a assimetria de informações e influencia na determinação dos preços de referência. Ainda, as comunidades virtuais são um espaço livre para as marcas estudarem os sentimentos dos internautas e o porquê desses indivíduos nutrirem sentimentos positivos ou negativos acerca de determinados serviços e produtos.

No entanto, as empresas, buscando maximizar os lucros e ao mesmo tempo satisfazer as demandas dos consumidores, necessitam desenvolver estratégias que possibilitem equacionar esses objetivos (LINDSTROM, 2016). E essas estratégias muitas vezes estão associadas à utilização da Internet como canal ou plataforma de comunicação fundamental.

Entre as possibilidades e ferramentas que a Internet propicia para a consolidação e utilização do Web marketing estão os Websites de comércio eletrônico, veículos utilizados pelas empresas na divulgação de seus produtos e serviços. Se utilizado de forma correta, possibilita as empresas resultados positivos no que diz respeito a lucrabilidade (OLIVEIRA et al, 2011, p. 149).

Para Neves (2018), com a integração das Tecnologias Digitais de Informação e Comunicação (TDIC), o profissional da informação é instigado para a inovação, com estratégias associadas a estas tecnologias como suporte de suas atividades técnicas e administrativas e de mediação da informação com os usuários. Assim,

[...] vários são os recursos tecnológicos que podem ser utilizados para potencializar suas atividades de interação, a exemplo de chats, microblogs, e-mail, videoconferência, fóruns, enquetes, principalmente por meio de celulares (smartphones), computadores. Um dos recursos mais modernos, e de baixíssimo custo, são os APP's ou aplicativos para celulares e outros dispositivos móveis, como os tablets, dentre outros. (NEVES, 2018, p. 219).

Especificamente, para a disponibilização e recuperação da informação, estratégias são utilizadas para melhorar o posicionamento dos Websites nos 
mecanismos de busca, sendo estes, atualmente, a principal forma de recuperação da informação disponível na Internet. Destaca-se, aqui, o SEO.

Percebe-se, portanto, que essas ações estratégicas com a utilização das TDIC disponíveis estão associadas a processos e atividades do marketing digital. Nesse sentido, tais atividades e processos - a serem potencialmente realizadas pelo profissional da informação - podem contribuir para a boa recuperabilidade da informação considerando o ambiente da Internet, possibilitando a disseminação da informação, e, consequentemente, a expansão do conhecimento, o que irá oportunizar às organizações alcançar seus objetivos institucionais relacionados especialmente ao marketing digital (OLIVEIRA et al, 2011).

\section{CARACTERÍSTICA DO SEO NA WEB}

No desenvolvimento de um projeto para a Web, um fator de muita importância e que normalmente é tratado como algo sem relevância pelos desenvolvedores, é a otimização do próprio projeto, seja ele um site ou uma simples página, para mecanismos de busca, o SEO. De acordo com Jerkovic (2010), o SEO é descrito como um conjunto de todo o trabalho necessário para produzir um alto volume de referências bem sucedidas oriundas de mecanismos de busca e diretórios Web com objetivo de popularizar um Website por meio da análise interna e externa de suas páginas, conteúdos e da quantidade de hiperlinks externos que apontem para essas páginas. Portanto, a adoção de metatags (campos que se referem a metadados), palavras-chave, além de estudos métricos de acessos e demais técnicas que visem a melhorar o posicionamento de páginas Web em motores compõem toda a estrutura de recursos que formam o SEO.

De acordo com Enge e outros (2012), o SEO, ao contrário de outras técnicas de marketing digital, como o Paid To Click (PTC)2, não precisa de grandes investimentos para ser implementado. Porém, é trabalhoso, uma vez

2 Ou Pago Por Clique (PPC), em português, como já diz seu próprio nome, é um modelo tradicional de negócio utilizado durante estratégias de marketing digital na Web em que o tráfego de um Website é originado de cliques em hiperlinks localizados em páginas de parceiros pagos (PAID..., 2020). 
que vários testes terão que ser feitos até se achar uma estratégia de SEO que efetivamente funcione para o conteúdo que o Website produz, mas, ainda assim, é uma estratégia que não exige grandes investimentos financeiros em publicidade, por exemplo.

Em grosso modo, o SEO funciona como uma propaganda gratuita que produz uma melhor taxa de retorno sobre o que é investido quando comparado com outros tipos ou estratégias de marketing digital, logo, percebe-se que 0 SEO não pode ser ignorado por empresas que querem se destacar e se manter vivas no mercado, principalmente aquelas que estão em fase inicial e não dispõem de muitos recursos.

É importante observar que o conteúdo produzido e de relevância dentro de uma estratégia de marketing digital continua ocupando um espaço singular e primordial, ainda mais no que diz respeito ao SEO, visto que ter um conteúdo original e de boa qualidade é uma causa para os efeitos de todas estratégias de SEO que forem utilizadas em um projeto Web. O SEO, neste caso, apenas levará o usuário ao conteúdo que o interessa, podendo ou não retê-lo na página que ele acessar. A diferença fica por conta de que por meio do SEO, o conteúdo positivo de um Website irá se sobrepor a infinidade de conteúdos mal indexados que existem na Web (JERKOVIC, 2010.)

As vantagens da utilização de técnicas de SEO são, dentre outras:

a) menor custo (bastam apenas recursos humanos e tempo);

b) benefícios em longo prazo duradouros;

c) crescimento natural do número de acessos no site; e

d) promoção da confiança (os resultados de busca orgânica passam uma maior confiança ao usuário quando comparados a hiperlinks pagos).

O SEO é um investimento com retorno em longo prazo, que exigirá o compromisso por parte da equipe de desenvolvimento, e não dá garantias de que o resultado esperado será atingido, pois, muitas vezes, os desafios de SEO não estão relacionados somente à tecnologia. Ledford (2007) cita os desafios enfrentados pelos analistas de SEO: 
a) com a expansão da Internet, o número de sites, segundo pesquisa realizada pela Netcraft em abril de 2009, era de cerca de 231,5 milhões em todo o mundo - o que já é um número gigantesco -, e levando em consideração que cada domínio pode conter vários subdomínios, é bem provável que o real número de sites esteja na casa de bilhões em 2019, um crescimento de mais de 33.000.000\%. Neste cenário, é difícil imaginar um nicho de mercado para se destacar da multidão;

b) falta de garantias: mesmo que você siga todas as estratégias de SEO, é impossível garantir que você conseguirá atingir o primeiro lugar nas pesquisas de um grande mecanismo de busca como Google, Yahoo! ou Bing. Há muitas variáveis envolvidas, e algumas estão fora do controle do desenvolvedor;

c) a utilização de SEO demanda tempo, mas, uma vez que você consiga ser bem sucedido, os benefícios são duradouros;

d) flutuação de ranques: os grandes mecanismos de busca são softwares proprietários de código fechado e possuem seus próprios fatores para a classificação das páginas disponíveis na Web. Assim, muitas vezes, a mudança de um desses fatores pode fazer com que o site caia algumas posições ou mesmo desapareça da tela de resultados nas buscas;

e) fator de tempo e constância: como já foi dito anteriormente o SEO é uma estratégia com resultados previstos a médio e longo prazo, e mesmo que você consiga o primeiro lugar nos mecanismos de busca, é necessário manter constância para continuar no topo, pois a concorrência pelas primeiras colocações é sempre muito grande.

De acordo com Enge et al. (2009), as estratégias de SEO podem ser aplicadas com várias finalidades:

a) SEO para tráfego puro: a otimização para mecanismo de busca e a criação de conteúdo direcionado a uma palavra-chave ajuda um site a aparecer para os principais termos da busca, o que 
normalmente leva a um tráfego direto e a hiperlinks de referência a medida que mais e mais pessoas passam a utilizar o que você produziu. Com a alta da publicidade online, milhares de sites utilizam desta estratégia para divulgar seus produtos e serviços por meio de banners e serviços como o Adsense, da Google. Este tipo de SEO deve ser empregado quando for possível monetizar o tráfego sem ações ou transações financeiras ocorrendo em seu site. Utiliza-se de estruturas inteligentes e categorias para um acesso mais fácil ao conteúdo do Website; seus artigos devem ser de fácil compartilhamento para que possam ser disseminados de forma viral;

b) SEO para lojas virtuais: uma das formas mais utilizadas de SEO é conduzir o tráfego relevante para uma loja eletrônica a fim de obter uma maior quantidade de vendas. Quando um usuário utiliza de um mecanismo de busca para procurar produtos e serviços, ele já sabe o que quer. Assim, se uma loja dispõe deste produto ou serviço e aplica adequadamente as técnicas de SEO para atrair esse potencial consumidor, as chances da venda ser bem sucedida são muito altas. Vale observar que somente é indicado fazer uso de SEO para lojas virtuais quando tiver produtos ou serviços a oferecer e que estes estejam disponíveis para venda em seu Website;

c) SEO para visibilidade: uma forma menos utilizada, mas muito poderosa de SEO é seu uso para dar visibilidade a uma marca. Esta estratégia é utilizada por blogueiros, influenciadores digitais, produtores de mídias, fornecedores de notícias e vários outros tipos de criadores de conteúdos digitais que queiram alavancar sua visibilidade aparecendo nos primeiros lugares nas páginas de resultados de pesquisas de grandes motores de busca. A utilização desta técnica é útil quando se deseja transmitir uma mensagem para qual não se tem ainda um conteúdo pronto ou 
bem definido. $O$ processo é similar à publicidade tradicional, ou seja, investe-se na repetição de um anuncio para que o mesmo se torne conhecido do comprador ou consumidor potencial. Para este tipo de SEO, a utilização de caudas longas, que é o uso de palavras-chave mais genéricas e em demasia, é o recomendável;

d) SEO para controle de reputação: a utilização de SEO para controle de reputação vem crescendo, pois é de grande interesse de grandes empresas manter sua reputação frente ao consumidor. Trata-se de um artifício utilizado contra as críticas sobre um produto ou serviço de determinada empresa, cujo objetivo é sobrepor as opiniões negativas dos consumidores com as opiniões positivas, posicionando-as entre os principais resultados de uma pesquisa e invisibilizando nas últimas páginas o conteúdo de teor negativo. O SEO para controle de reputação é uma das maiores dificuldades que o profissional de SEO pode ter, pelo fato de envolver não somente um, mas vários resultados entre as melhores colocações nos mecanismos de busca. Este é um mercado em extrema ascensão devido à consciência das empresas de que precisam manter uma reputação impecável frente ao seu consumidor e às pessoas que ainda não conhecem seus produtos ou serviços;

e) SEO para influência ideológica: o uso de SEO para influência ideológica procura dominar a opinião pública sobre um determinado assunto. $\mathrm{O}$ objetivo aqui é promover ideias $\mathrm{e}$ conteúdos enviesados ideologicamente dentro dos resultados dos mecanismos de busca para que pessoas que tenham interesse nos assuntos discutidos na perspectiva de uma determinada ótica. Muitos políticos utilizam esta técnica para divulgar seus feitos, porém qualquer pessoa, seja ela pública ou não, pode fazer uso desta estratégia para influenciar pessoas e grupos.

Segundo Trevisan, Monteiro e Vidoti (2019), no mundo digital, o 
entendimento e uso dos mecanismos de busca ainda são obscuros àqueles que estudam a organização, recuperação e disseminação da Informação sob o olhar da Ciência da Informação, uma vez que os critérios de indexação são restritos às empresas de busca. Endossamos, a esta observação, que também o volume de publicações sobre o SEO na literatura da área, no Brasil, ainda é tímido.

\section{O CASO DO WEBSITE DO PERIÓDICO “PONTODEACESSO”}

O Website da revista científica PontodeAcesso, então editada pelo Programa de Pós-Graduação em Ciência da Informação da Universidade Federal da Bahia (PPGCI-UFBA) e gerenciada por meio da plataforma Open Journal Systems (OJS), foi escolhida como o objeto de estudo desta pesquisa. Assim, propondo uma análise prática, objetiva e estritamente técnica no que diz respeito às estratégias de SEO on-site e on-page, os dados aqui elencados e estudados vão ao encontro de uma sugestão de intervenção técnica que possa especificamente potencializar um determinado aumento da recuperação da informação já indexada pelo site em suas páginas, inclusive aquela relacionada aos metadados de suas produções científicas 3 .

A PontodeAcesso é um periódico científico que publica as produções mais recentes na área da Ciência da Informação e matérias próximas, tendo como potenciais públicos os estudantes, professores, pesquisadores e profissionais da Informação e de áreas afins, sobretudo Bibliotecários, Arquivistas, Museológicos e entre outros.

No campo do marketing digital, uma das formas mais indicadas de se conhecer um público e entender suas necessidades diante de um produto ou serviço é transformando-o em personas, ou seja, personagens semi-fictícios que se aproximem das características gerais do público e apresentem suas principais demandas. Por isto, visando melhor compreender o público da PontodeAcesso e suas necessidades em relação às limitações do site no

\footnotetext{
3 É importante observar que, neste estudo, foram consideradas as limitações técnicas da plataforma OJS, o que justifica, portanto, que algumas das soluções apresentadas podem ser apenas exemplificativas.
} 
quesito SEO, determinamos três personas com base nas recomendações de Lovelock e Wirtz (2007) e Neves (2018):

a) Jair, o graduando alheio a bibliotecas e bases de dados: de Curitiba, tem 22 anos e acabou de ingressar no bacharelado de Pedagogia. Não faz ideia do que seja um periódico, pois nasceu em uma época em que tudo está no Google a poucos cliques. Também não se importa com referências confiáveis: para ele, se está na Internet, é verdade;

b) César, o professor pesquisador e publicador: 48 anos, leciona na área da Administração Pública e mora no Rio de Janeiro. César é deficiente visual e nunca the falta reclamações acerca de uma Internet pouco acessível e inclusiva. Por ser um pesquisador bastante atento às novidades do seu campo de atuação, vive publicando artigos em diversas revistas científicas, inclusive de áreas comuns a sua; $\mathrm{e}$

c) Cassandra, a profissional em pesquisa digital: bibliotecária habilidosa, tem 32 anos e reside em Recife, capital de Pernambuco. Domina os motores de busca e as caixas de pesquisa das mais importantes bases de dados e revistas na área de Ciência da Informação. Considera conteúdo de qualidade aquele que é oriundo de fontes confiáveis.

Definidas as personas, conhecemos as principais limitações do site no sentido de SEO. Assim, podemos realizar uma análise mais incisiva sobre pontos que potencialmente diminuem a encontrabilidade das informações da PontodeAcesso em motores de busca, considerando medidas de SEO on-site e on-page ${ }^{4}$.

\footnotetext{
${ }^{4}$ Aqui optou-se por analisar a indexação da PontodeAcesso exclusivamente no Google devido a sua popularidade entre os motores de busca. Todas as pesquisas foram realizadas em uma janela anônima do navegador Google Chrome, na data de 31 de janeiro de 2020, evitando assim que registros de navegação e buscas anteriores influenciassem os resultados das pesquisas.
} 


\subsection{MedidAS DE SEO ON-Site}

SEO on-site diz respeito às estratégias e técnicas de SEO que focalizam no todo de um Website, ou seja, em toda a estrutura visível e interna (códigofonte), inclusive suas páginas afluentes (SEO..., 2020). Dada as limitações da pesquisa, adotaremos para análise apenas a página inicial da PontodeAcesso tal como é vista ao ser acessada, assim como trechos do seu código-fonte, sua estrutura interna.

De acordo com a primeira persona, podemos destacar que a PontodeAcesso apresenta suas informações de maneira pouco atrativa para públicos que não conhecem ou têm pouco interesse em revistas científicas eletrônicas, ou seja, um grupo potencial que não acessaria a página diretamente (digitando o endereço do site no navegador, por exemplo). Além disso, as informações principais e gerais do Website são potencialmente mal indexadas de acordo com os ditames do SEO, caso do próprio nome da revista, não aparecendo, portanto, entre os principais resultados de pesquisa em um motor de busca popular como o Google.

\section{Figura 1 - Resultado para a pesquisa no Google tendo como expressão de busca o título da revista em grafia convencional}

\begin{tabular}{|c|c|}
\hline Google & ponto de acesso \\
\hline & 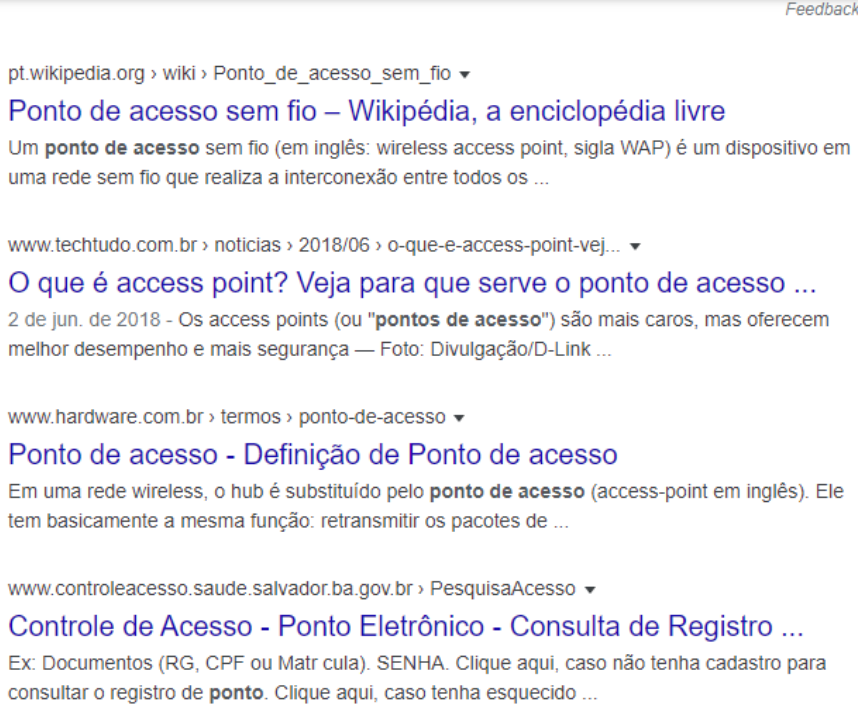 \\
\hline
\end{tabular}

Fonte: Reprodução / Google (2020). 
A Figura 1 demonstra como pode ser prejudicial, em termos de recuperação em motores de busca, a simples adoção de uma grafia estilística não convencional para uma informação tão relevante quanto é o título da revista, que, neste caso, representa o título de todo o Website da PontodeAcesso, principal metadado de uma página Web.

O objetivo básico de um ser humano é obter informações que sejam relevantes para sua vida. De acordo com Enge et al (2012), um dos elementos mais importantes para criar uma estratégia de marketing digital em torno do SEO e das classificações que envolvem a busca é desenvolver um entendimento meticuloso do comportamento de busca da sua persona.

Nessa perspectiva, nenhuma das 'personas' determinadas neste estudo recuperariam a Revista. É importante considerar que as buscas na Internet são indubitavelmente são uma das melhores maneiras de atingir usuários e criar uma rede.

Figura 2 - Trecho do código-fonte da PontodeAcesso com os metadados "<meta... / >" e "<title $></$ title>" da página principal do Website

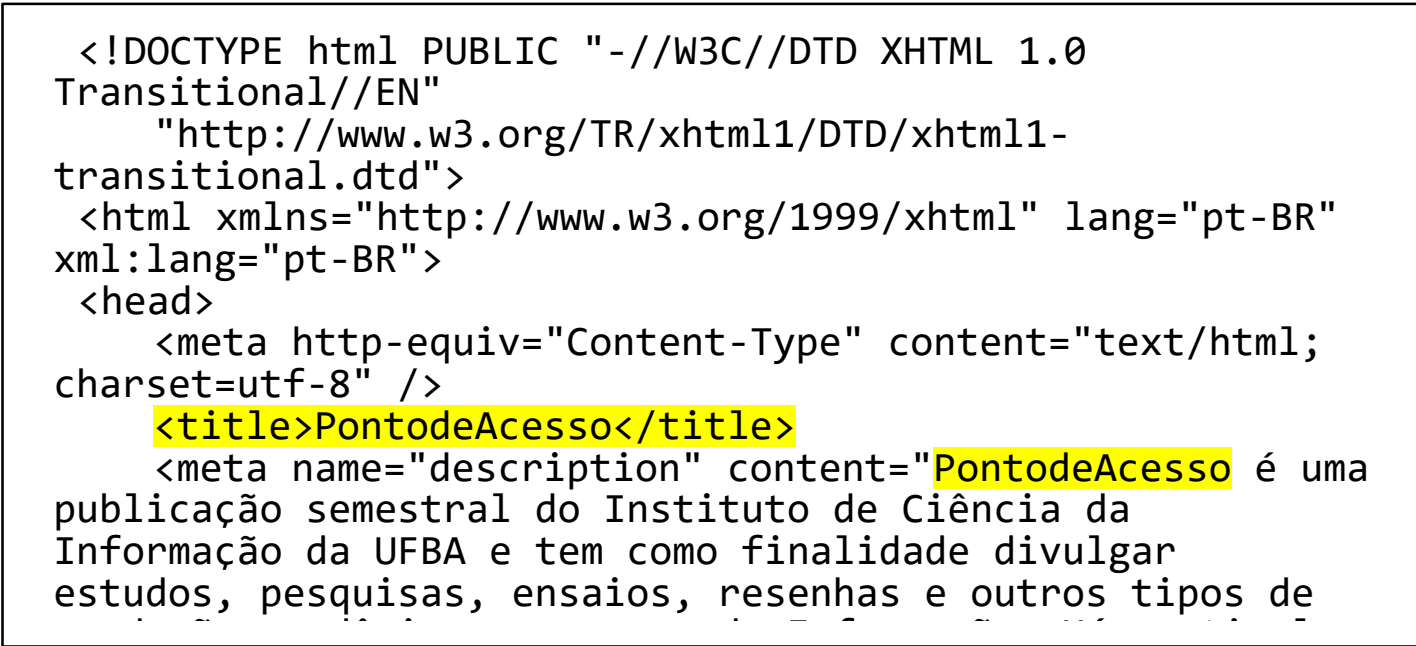

Fonte: Reprodução / PontodeAcesso (adaptado).

Nos trechos destacados da Figura 2 é possível confirmar que a metadescrição do site por meio dos seus metadados não abrange formas alternativas de escrita do título da revista, o que restringe demasiadamente a chance de se encontrar as páginas da PontodeAcesso em uma pesquisa despretensiosa no Google, ou seja, durante uma busca orgânica. 
Segundo Araújo e Neves (2019), as buscas orgânicas são extremamente populares e os usuários tendem a usar frases curtas nos mecanismos de busca, mas gradualmente as frases tem ficado mais extensas, sendo relevante antecipar o que o usuário digitaria. O Google é o player mais dominante quando o quesito é busca na Web. Desse modo, os sites precisam estar preparados para escalar em motores e algoritmos que cobrem todos os tipos de mercados (NEVES, 2018a).

Em si tratando de recuperação da informação, concordamos com Vieira e Pinho (2015, p.112) "[...] que a eficácia de um sistema que lida com a recuperação da informação está diretamente relacionada à inteligência adotada para a sua organização [...]" e com a maneira que este elemento se relaciona os dados não visíveis e metadados.

Figura 3 - A PontodeAcesso recuperada no mecanismo de busca usando a grafia estilística do seu nome

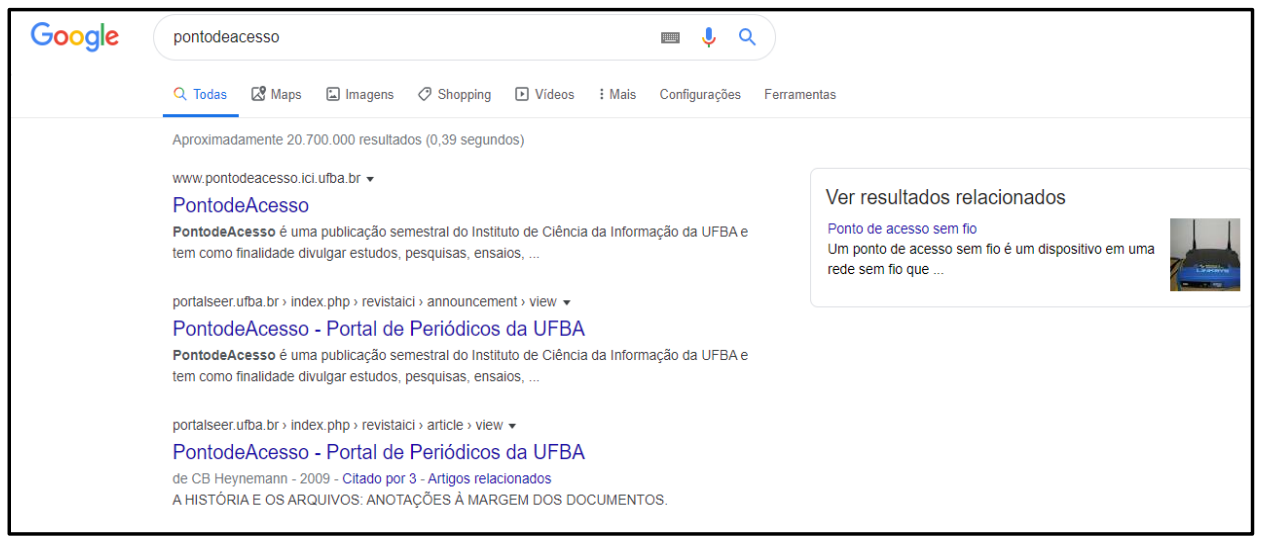

Fonte: Reprodução / Google (2020).

Sendo feita a busca usando a grafia "PontodeAcesso", sem espaços, como mostrado na Figura 3, a revista prontamente é recuperada pelo motor de busca. Vale observar, no entanto, que potenciais usuários que poderiam acessar a revista dificilmente adivinharia que é esta a forma de escrever o título do periódico. Caso tivesse, dentre os metadados, a forma "Ponto de Acesso", com espaços, a busca resultaria positiva tanto agora quanto na Figura 1, garantindo maior visibilidade ao periódico e aumentando a quantidade de acessos em suas páginas. Enge et al (2012) irá dizer que a recuperação da 
informação é favorecida a partir de técnicas de SEO, independe se estamos tratando, seja de usuário ou de consumidores, e seja qual for o tamanho, localização do produto-serviço-negócio em questão.

Figura 4 - Trecho do código-fonte da PontodeAcesso com os metadados de descrição da página principal do Website

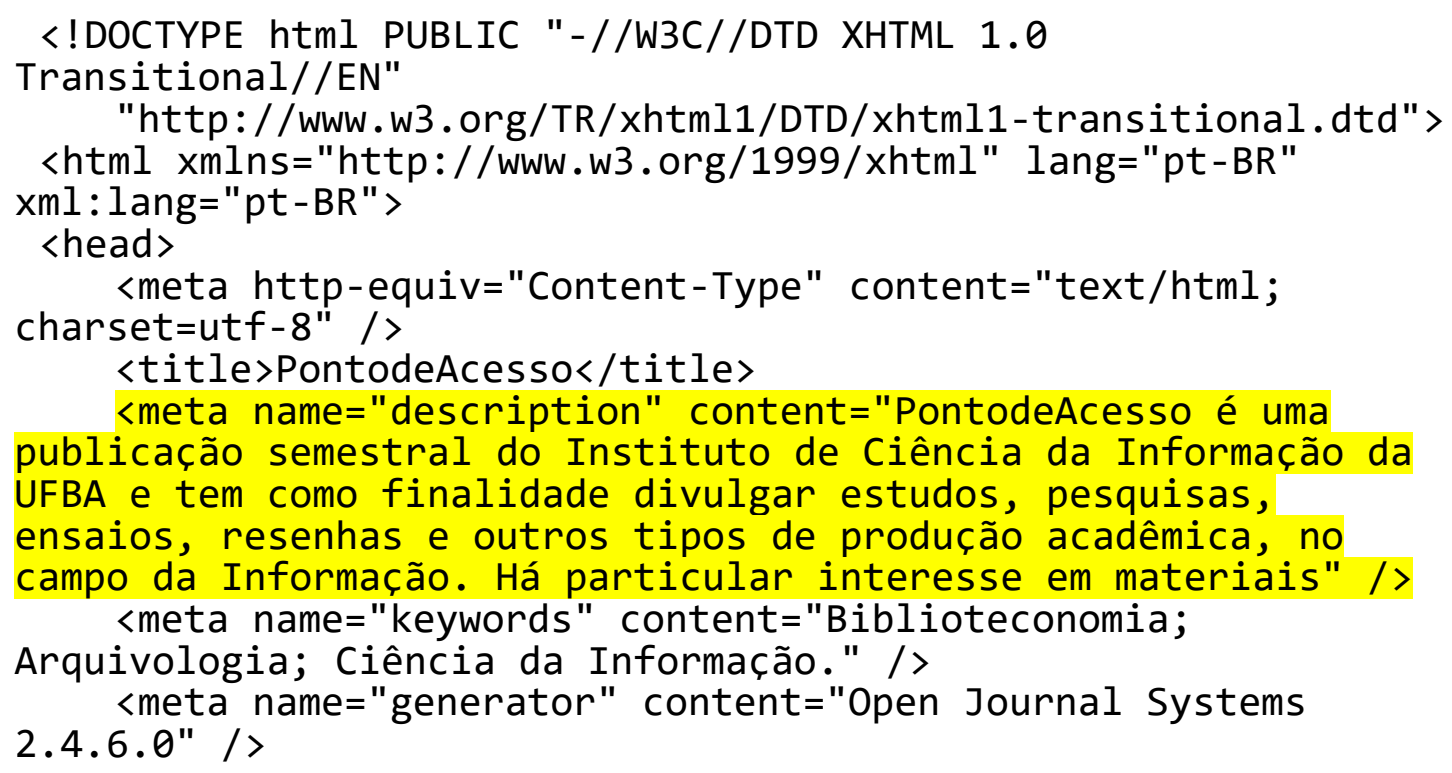

Fonte: Reprodução / PontodeAcesso (adaptado).

A Figura 4 destaca os metadados que dizem respeito à descrição de uma página Web, neste caso, da página principal do Website da PontodeAcesso. Vale observar que a descrição de uma página tem limitação de caracteres, uma vez que, quando esses dados são recuperados em um mecanismo de busca, há um espaço textual curto. Além disso, trata-se de um campo que exige objetividade e estratégia durante seu preenchimento, buscando sempre abarcar resumidamente os termos-chave mais relevantes em relação ao site.

Para Enge et al (2012), a otimização para mecanismos de busca e a criação e direcionamento de palavras-chave ajuda um site aparecer para os principais termos de busca. 
Figura 5 - A descrição do site indexada no motor de busca

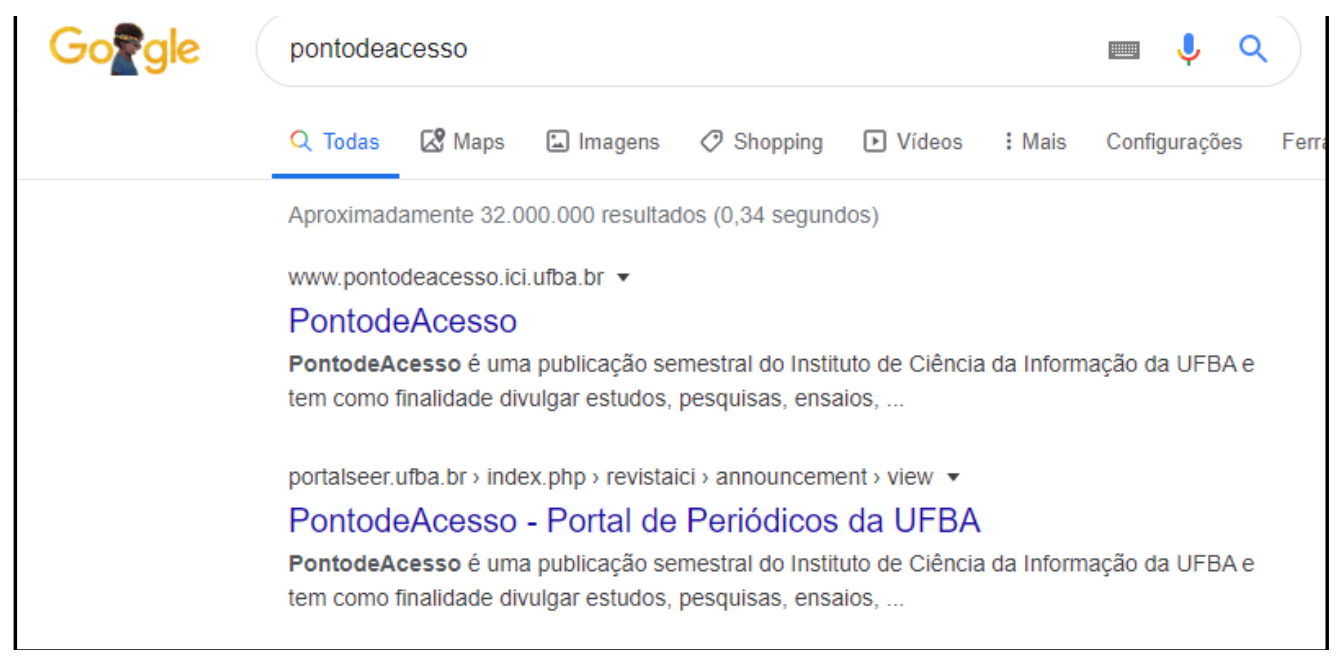

Fonte: Reprodução / Google.

Como pode ser visto na Figura 5, a descrição da página é recuperada de forma incompleta. E um agravante: não apresenta palavras-chave que sejam relevantes ou que já não estejam presentes em outros campos de metadados, a exemplo do próprio nome da revista, que se repete no campo "<title ...></title>" da página. Em substituição, uma ótima sugestão seria adotar a grafia convencional do título da revista neste campo, além de termos que pudessem se relacionar à região Nordeste ou a temas relevantes específicos em que a revista vem trabalhando.

As palavras-chave propriamente ditas de uma página Web localizam-se geralmente dentro do metadado "keywords". No caso da PontodeAcesso, podemos observar que o campo é pouco aproveitado, posto que faz uso de apenas três termos que certamente restringem demasiadamente sua indexação em um mecanismo de busca popular.

Nesse contexto Enge et al (2012) sugerem que se concentrem esforços em um excelente conteúdo e seja utilizada a otimização baseada em palavraschave somente como método secundário para confirmar os títulos, manchetes, time-lines que são possíveis ser criadas, visando um trafego puro. Uma medida que poderia ser adotada é a atualização constante desse campo a medida que a revista tivesse novos números publicados, oportunidade em que o campo seria preenchido com termos relevantes relacionados aos artigos publicados. 
Figura 6 - Página inicial da PontodeAcesso

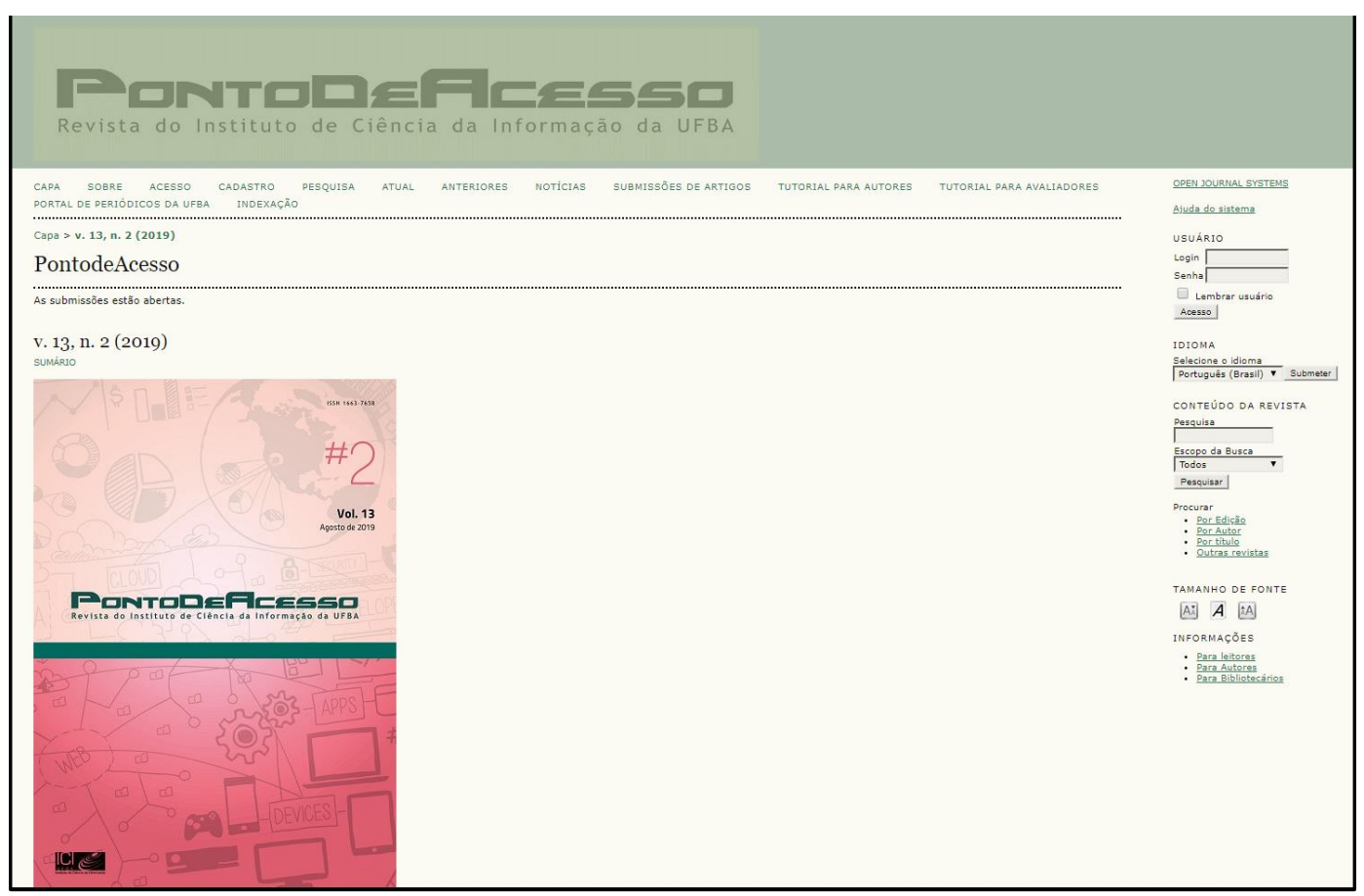

Fonte: Reprodução / PontodeAcesso.

A Figura 6 traz a visualização padrão da página inicial da revista PontodeAcesso em um computador de mesa, e aqui podemos apontar a ausência de recursos de acessibilidade para deficientes visuais. Neste caso, uma persona como César teria dificuldades em navegar na página e encontrar o que deseja. Falta, por exemplo, autodescrição das imagens para leitores de tela, o que inclusive acontece na principal informação de uma página Web: o nome da página. Ao entrar no site, o nome da revista é carregado em uma imagem, em formato de logotipo, e esta não apresenta autodescrição. Não obstante, além de não ser legível para pessoas com limitações visuais, é potencialmente ilegível para usuários com conexão precária de Internet. A medida mais indicada seria, neste ponto, substituir a imagem por seu nome em texto puro, ou então adicionar metadados legíveis no código de inserção da figura.

Neste mesmo contexto, percebe-se também a falta de uma breve apresentação da revista, em texto, no topo ou no rodapé da sua página principal. Informações como essas são valorizadas por motores de busca, além 
de que ajudam os usuários a saberem exatamente o que estão acessando (ARAÚJO; NEVES, 2019).

Por fim, no que tange a aspectos de SEO on-site para a revista PontodeAcesso, podemos analisar o baixo potencial de uso dos poderes dos metadados de páginas Web. Como podemos observar novamente no trecho de código-fonte da página principal da revista, ocorreu o uso de apenas dois campos de metadados que são importantes para uma boa estratégia de SEO: descrição da página ("description") e palavras-chave ("keywords"). As informações preenchidas no metadado "<title ...<</title>", "Content-Type" e "generator" são automáticas, e possivelmente seu preenchimento não foi pensado de maneira estratégica no sentido de SEO.

As técnicas e estratégias de boa indexação em motores de busca são inúmeras, e os campos de metadados são diversos, podendo ser usados tanto para restringir buscas (funcionando como "filtros") quanto para captar novos públicos, prezando pela generalização de metadados. Podemos citar campos como os que restringem países, idiomas de busca, para solicitar visitas de robôs de mecanismos; ou estratégias básicas, como a implementação de um mapa de site indexado ou a adoção de endereços amigáveis de páginas e recursos do site.

\subsection{Medidas de SEO ON-PAGE}

O SEO on-page observa aspectos mais voltados ao formato, descrição e indexação do conteúdo de um site e suas páginas internas. Logo, ele é mais específico e se relaciona intimamente com o marketing digital de conteúdo. $O$ objetivo desse tipo de análise SEO está, portanto, em criar conteúdo relevante, organizado e original, em sua forma e em sua apresentação, para que buscadores populares possam indexar esse conjunto de informações de maneira mais eficaz (SEO..., 2020). Para esta pesquisa, analisamos apenas as páginas "Sumário", onde se encontra o sumário do número vigente da revista, e a página de um artigo aleatório.

Uma das estratégias mais indicadas para uma boa indexação em 
mecanismos de busca é a de se estruturar e padronizar blocos ou seções de um texto ou páginas, separando-os com títulos indicadores em formatos e padrões definidos. Como podemos ver na Figura 7 a seguir, o sumário é apresentado de maneira estruturada, atendendo a uma formatação padrão para tipos diferentes de informação, assim como separando e indicando os artigos em relação aos ensaios, e os autores recebendo uma formatação diferente, por exemplo.

Outro ponto positivo a favor da PontodeAcesso nesta página é a disponibilização dos títulos de cada artigo de maneira clicável, sem fazer uso de termos como "clique aqui" para indicar um hiperlink, recurso este muito repudiado por motores de busca.

Figura 7 - Página interna "Sumário" da PontodeAcesso

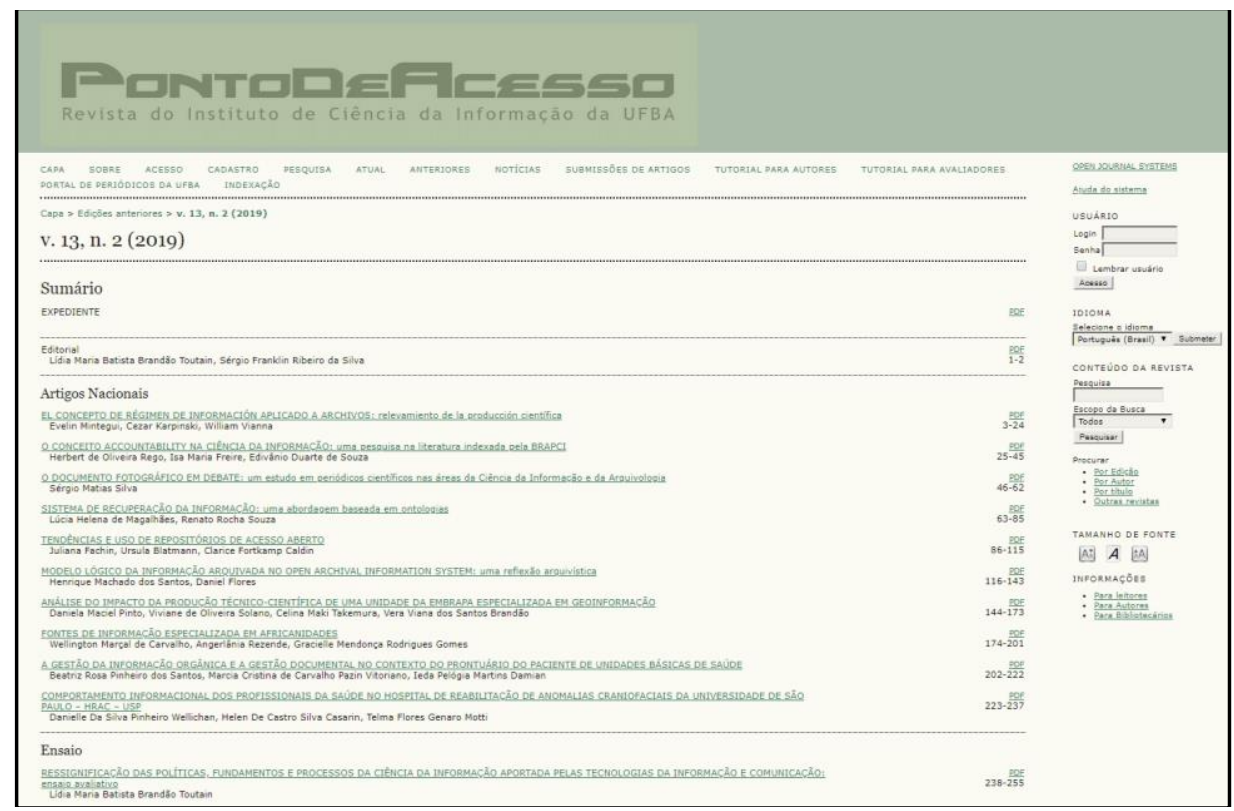

Fonte: Reprodução / PontodeAcesso.

A persona Cassandra, uma Bibliotecária que domina as técnicas e estratégias de busca em motores de busca e bases de dados, talvez não encontrasse as produções da PontodeAcesso, posto que a forma em que suas páginas são indexadas não contemplam termos-chave, inclusive em inglês, que Cassandra usaria em suas buscas avançadas.

Tal situação ocorre porque em sua página específica de artigo, a PontodeAcesso não abusa dos metadados, inclusive quando as informações 
que poderiam ser usadas para preencher esses campos já existem no próprio artigo, bastando apenas copiá-las. É o caso do resumo e palavras-chave em língua inglesa, tradicionais e itens obrigatórios em qualquer artigo científico nacional. A Figura 8 demonstra essa falta: a PontodeAcesso indexa somente 0 título, autores e resumo em Português da produção científica, o que "[...] limita bastante a visibilidade e divulgação internacional do artigo por parte do Website em motores de busca" (ENGE et al, 2009, p. 201, tradução livre).

Figura 8 - Página interna de um artigo da PontodeAcesso

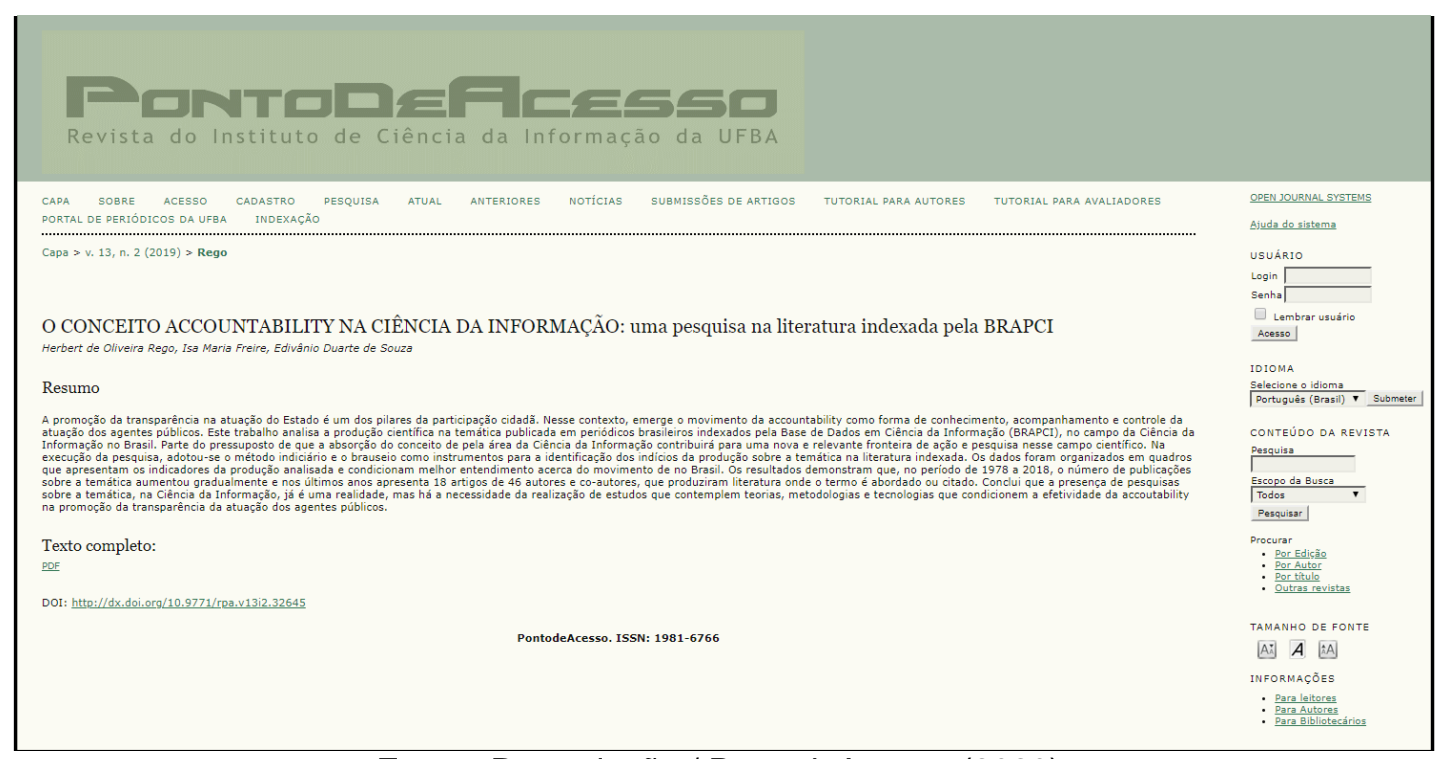

Fonte: Reprodução / PontodeAcesso (2020).

Aqui se repete o que foi analisado na subseção anterior: a PontodeAcesso, assim como a grande parte das revistas científicas nacionais, não utiliza ou desconhece todo o potencial que as técnicas e estratégias de SEO on-site e on-page podem Ihe oferecer. Desta forma, seu conteúdo é pouco ou mal indexado pelos principais mecanismos de busca, uma vez que falta ao Website da PontodeAcesso a adoção de metadados relevantes para ampliar, ou possibilitar em alguns casos, a visibilidade, recuperação e engajamento de suas informações. Nesse caso, interessados em trilhar o caminho do marketing científico digital devem se dedicar a três questões essenciais: (a) a construção e manutenção de uma presença on-line; (b) a promoção de conteúdo adequado aos ambientes que atuar e; (c) a atuação responsiva (ARAÚJO, 2018). 
A perspectiva de marketing é essencial para o gerenciamento da provisão de serviços de informações e requer uma abordagem comercial para o mercado e os negócios da informação, visando aumentar a visibilidade da abrangência e abrangência do aplicativo e uso da Ciência da Informação (AMARAL, 2017).

Concordamos com Araújo e Neves (2019), que o atual nível de conectividade da ciência exige que os autores procurem formas criativas e mais adaptadas para o compartilhamento, visando apoiar as revistas na difusão de suas comunicações científicas na Internet. Contudo, entendemos que os periódicos precisam desenvolver boas práticas e estratégias de marketing de conteúdo digital nas redes sociais e de SEO, dando início pelas técnicas onpage que dizem respeito ao formato, descrição e indexação de conteúdos.

A subutilização de técnicas on-page restringe o acesso às produções publicadas pela revista e pode impossibilitar sua visibilidade a nível global por meio de buscadores populares como Google, Bing e Yahoo!.

\section{CONSIDERAÇÕES FINAIS}

O marketing digital mudou as relações de mercado. Agora, o consumidor tem voz e a sua escolha não depende mais somente da própria empresa, mas de inúmeros aspectos que não podem ser controlados por uma única instituição. A informação ampla e facilmente compartilhável no campo da Internet ganhou níveis jamais vistos, e com isso o marketing tradicional precisou se reinventar, deixando de lado estratégias antes custosas e pouco acessíveis, para adotar medidas focadas em todos ao mesmo tempo, do José do interior do Ceará a Fátima da capital do Brasil, do William em Nova Iorque ao Murilo em Xangai. Seja por meio de plataformas, de redes sociais ou simplesmente em suas páginas institucionais extremamente dinâmicas e interativas, as empresas estão dia a dia tendo que direcionar seus orçamentos de publicidade mais para pagar Youtubers e Digital Influencers que possam avaliar positivamente seus produtos ou serviços do que para estampar sua marca em comerciais televisivos em horário nobre. 
No meio de toda esta dinâmica e tamanha revolução, o SEO emerge como uma alternativa pouco custosa, mas eficiente, de se destacar uma marca ou divulgar um conteúdo. Websites que adotam essas técnicas não escondem seus resultados positivos: basta uma rápida busca por determinados termoschave que páginas já conhecidas do público, mas que nem sempre são referências em um dado assunto, estão lá, entre os primeiros do Google.

O Website da revista PontodeAcesso tem conteúdo de qualidade, escrito por pessoas de referência e de autoridade inquestionável sobre os mais diversos assuntos no campo da Informação. Mas o quanto tudo isso aparece para o mundo? Talvez muito pouco.

A implementação de estratégias e técnicas de SEO on-site e on-page têm grande potencial para melhorar tal ponto, o que infelizmente não pode ser ainda visto no site da revista estudada. O que se vê, no entanto, é uma adoção ínfima, provavelmente despretensiosa e inocente, de parte mínima do básico do que o SEO tem a oferecer.

Diante disso, finalmente concluímos que o Website da PontodeAcesso não faz uso de técnicas e estratégias SEO on-site e on-page, uma vez que seu conteúdo produzido e publicado não pode ser atualmente recuperado em buscas básicas por meio dos principais buscadores da Internet. Logo, acreditamos que, provavelmente, seu conteúdo dificilmente será acessível por comunidades e usuários internacionais - e nacionais - que detenham algum interesse nas suas temáticas. Pelo menos de maneira orgânica. Isto é, por meio de acessos unicamente oriundos de resultados de mecanismos de busca com uso de palavras-chave relevantes.

\section{REFERÊNCIAS}

AMARAL, S. A. do. Users, information consumers, and information service agencies from the marketing perspective. Transinformação, Campinas, v. 29, n. 1, p. 27-38, 2017 . Disponível em: https://doi.org/10.1590/231808892017000100004. Acesso em: 22 Mar. 2020.

ARAUJO, R. F. Marketing científico digital e métricas de mídias sociais: indicadoreschave de desempenho de periódicos no Facebook. Informação \& Sociedade: 
Se estou no Google, logo existo: técnicas de alavancagem e visibilidade de um periódico científico em motores de busca por meio de técnicas de SEO

Estudos, João Pessoa, v. 28, p. 7-22, 2018. Disponível em: https://doi.org/10.22478/ufpb.1809-4783.2018v28n1.22063. Acesso em: 22 março 2020.

ARAUJO, R.F.; NEVES, B. Coelho. Marketing de conteúdos digitais: o uso das redes sociais na pesquisa. In: SANTOS, G. C.; MARTINS, V. dos S. G. (orgs.). Ciência aberta, sistemas e ambientes de informação: do acesso às boaspráticas de pesquisa. Campinas, SP: Ed.NE-SBU, 2019.

ARAÚJO, W. S.; FREIRE, G. H. A.; CÔRTES, G. R. Marketing de relacionamento em bibliotecas: estratégia de comunicação em ambiente Web. Informação \& Informação, Londrina, v. 23, n. 3, p. 544-564, dez. 2018. Disponível

em:http://www.uel.br/revistas/uel/index.php/informacao/article/view/28282. Acesso em: 22 mar. 2020. doi: http://dx.doi.org/10.5433/1981-8920.2018v23n3p544.

ENGE, E. et al. The art of SEO: mastering Search Engine Optimization. Beijing: O'Reilly, 2012. 574 p.

FREDERICO, E. O que é marketing?. Antenna Web, ed. 4, p. 1-8, semestre 2008. Disponível em: https://www.antennaweb.com.br/edicao4/artigos/pdf/ed4.pdf. Acesso em: 2 fev. 2020.

JERKOVIC, J. I. SEO warrior. California: O'Reilly, 2010.

KOTLER, P. Marketing 3.0: as forças que estão definindo o novo marketing centrado no ser humano. Tradução Ana Beatriz Rodrigues. Rio de Janeiro: Elsevier, 2012.

KOTLER, P.; KARTAJAYA; H.; SETIAWAN, I. Marketing 4.0: do tradicional ao digital. Rio de Janeiro: Sextante, 2017.

LINDSTROM, M. A lógica do consumo: verdades e mentiras sobre por que compramos. Rio de Janeiro: Harper Collins, 2016.

LOVELOCK, C.; WIRTZ, J. Marketing de serviços: pessoas, tecnologia e resultados. São Paulo: Pearson, 2007.

MORETTI, S. L. do A.; OLIVEIRA, S. L. I.; SOUZA, C. G de. A evolução do conceito de marketing e sua aplicação no turismo: simetrias evolutivas, assimetrias temporais.

Revista de Turismo Contemporâneo, Natal, v. 6, n. 1, p. 129-150, jan./jun. 2018. Disponível em: https://periodicos.ufrn.br/turismocontemporaneo/article/view/12477. Acesso em: 2 fev. 2020.

NEVES, B. C. Marketing digital para instituições educacionais: e sem fins lucrativos. New York: Amazon, 2018.

NEVES, B. C. Strategist librarian on social media: conceptual approach and possibilities of digital marketing in public libraries Informação \& Sociedade: Estudos., João Pessoa, v.28, n.3, p. 323-337, set./dez. 2018.

OLIVEIRA, A. M. de et al. Search Engine Optimization - SEO: a contribuição do bibliotecário na otimização de Websites para os mecanismos de busca. Perspectivas em Gestão \& Conhecimento, João Pessoa, v. 1, número especial, p. 137-159, out. 
Barbara Coelho Neves, Ramon Davi Santana, Dulcinéia Vieira de Assunção Gomes, Makson de Jesus Reis

Se estou no Google, logo existo: técnicas de alavancagem e visibilidade de um periódico científico em motores de busca por meio de técnicas de SEO

2011. Disponível em: https://periodicos.ufpb.br/ojs2/index.php/pgc/article/view/10792. Acesso em: 2 fev. 2020.

PAID TO CLICK. In: WIKIPÉDIA, a enciclopédia livre. Flórida: Wikimedia Foundation, 2020. Disponível em:

https://pt.wikipedia.org/w/index.php?title=Paid_to_click\&oldid=55961805. Acesso em: 2 fev. 2020.

SEO: tudo sobre Search Engine Optimization. Resultados Digitais, 2020. Disponível em: https://resultadosdigitais.com.br/especiais/o-que-e-seo. Acesso em: 2 fev. 2020.

TERBLANCHE, N.S. A century of marketing: achievements, mishaps and future challenges, Management Dynamics, 14(4), p.1-17, 2005.

TREVISAN, G. L.; MONTEIRO, S. D.; VIDOTTI, S. A. B. G. Search engine optimization e qualidade das fontes de informação digital: elementos construtores à busca.

Perspectivas em Gestão \& Conhecimento, v. 9, n. 2, p. 4-23, 2019. Disponível em: http://hdl.handle.net/20.500.11959/brapci/121067. Acesso em: 22 mar. 2020.

VIEIRA, J.M.L.; PINHO, F. A. A contribuição da organização e da visualização da informação para os sistemas de recuperação de informação. Informação \&

Informação, Londrina, v. 20, n. 1, 2015. Disponível em: < http://www.uel.br/revistas/uel/index.php/informacao/article/view/17815>. Acesso em: ago., 2020.

\title{
IF I'M ON GOOGLE, SO EXIST: LEVERAGE AND VISIBILITY STRATEGIES OF A SCIENTIFIC JOURNAL IN SEARCH ENGINES USING SEO TECHNIQUES
}

\begin{abstract}
Introduction: The article addresses digital marketing through the search engine optimization (SEO) techniques applied to the case of the website of the scientific magazine PontodeAcesso.. Objective: It analyzes objective and technical aspects and measures of SEO on-site and on-page that promote the leverage of the visibility of the site and its published content among the main search results of major search engines such as Google, Bing and Yahoo !. Methodology: The method is descriptive, with a qualitative approach, and case study methodology (Magazine) in marketing, with the support of literature review and observation technique based on the creation of personas. Results: As a result, the text presents in a descriptive and grounded way the observations made from the analysis from the perspective of on-site and on-page SEO.. Conclusions: It is concluded that the PontodeAcesso website does not use such strategies and techniques, which has contributed to a potential invisibility or low recovery of its scientific production on the Web in search engine results at a global level. And that the use of such tools could increase its visibility in the scientific community and enhance the engagement.
\end{abstract}

Descriptors: Web search tools. Internet marketing. Information retrieval. Search Engine Optimization (SEO). Scientific journal. 


\title{
SI ESTOY EN GOOGLE, LOGO EXISTO: TÉCNICAS DE APALANCAMIENTO Y VISIBILIDAD DE UNA REVISTA CIENTÍFICA EN BUSCADORES A TRAVÉS DE TÉCNICAS SEO
}

\begin{abstract}
RESUMEN
Introducción: El artículo trata sobre el marketing digital en las técnicas de optimización en buscadores (SEO) aplicadas al caso del sitio web de la revista científica PontodeAcesso. Objetivo: Analiza aspectos y medidas objetivas de SEO onsite y on-page que promueven la visibilidad del sitio y su contenido publicado entre los principales resultados de los motores de búsqueda como Google, Bing y Yahoo!. Metodología: El método es descriptivo, con enfoque cualitativo, y metodología de estudio de caso (Revista) en marketing, con el apoyo de la revisión de la literatura y la técnica de observación desde la creación de personajes. Resultados: el texto presenta de forma descriptiva y fundamentada las observaciones realizadas a partir del análisis desde la perspectiva del SEO on-site y on-page. Conclusiones: el sitio web de la revista PontodeAcesso no utiliza tales estrategias y técnicas, lo que ha contribuido a una potencial invisibilidad o baja recuperación de su producción científica en la Web en los resultados de los buscadores a nivel global. Y que el uso de tales herramientas podría aumentar su visibilidad en la comunidad científica y mejorar el compromiso.
\end{abstract}

Descriptores: Herramientas de búsqueda web, marketing en Internet. Recuperación de información. Optimización de motores de búsqueda (SEO). Periódico científico.

Recebido em: 22.03.2020

Aceito em: 04.08 .2020 